\title{
¿Qué significa la transmisión de la tradición desde la historia? Entrevista con Joseph Moingt S. J. sobre Michel de Certeau*
}

\author{
GUILLERMO AUGUSTO MÚNERA DUEÑAS \\ Y GUILLERMO ZERMEÑO PADILLA
}

Considering History, What Does the Tradition's Transmition

Mean? Interview with Joseph Moingt S. J. about Michel de Certeau

Guillermo Augusto Múnera Dueñas École Pratique des Hautes Études-Paris Sciences et Lettres, Groupe Sociétés Religions, Laïcités, París, Francia memoaugus@hotmail.com

GUILLERMO ZERMEÑO PADILLA

El Colegio de México, Ciudad de México, México gmoz@colmex.mx

Desacatos 58 , septiembre-diciembre 2018, pp. 184-197 ichel de Certeau es uno de los pensadores más influyentes de la llamada generación del 68. Sus contribuciones son conocidas en ámbitos disciplinarios tan diversos como las relaciones entre historia y psicoanálisis, la antropología y la historia, así como la sociología de la cultura. Son menos conocidas en el campo académico, en cambio, su formación como filósofo y teólogo. En esos terrenos, puede decirse, De Certeau y Moingt son compañeros cercanos de ruta, como integrantes del movimiento de renovación de la teología cristiana, católica y protestante. Desde ese lugar pueden entenderse también las contribuciones de De Certeau a las ciencias sociales y humanidades a partir de la década de 1970: como respuesta a una crisis global de la cultura occidental, no circunscrita sólo a una crisis de la cristiandad. ${ }^{1}$

Esta entrevista fue realizada en París entre mayo y junio de 2017. El padre Joseph Moingt, de la Compañía de Jesús, aceptó recibirnos en la comunidad jesuita de la rue de Grenelle y autorizó la grabación de dos entrevistas. Con el buen sentido del humor que lo caracteriza, nos pidió que no enviáramos la publicación al Vaticano. Después de una breve presentación, Guillermo Zermeño explicó al padre Moingt sus líneas de trabajo y su relación con el pensamiento de Michel de Certeau. La creación de la revista Historia y Grafía, publicada por la Universidad Iberoamericana, es uno de los proyectos inspirados por el pensamiento del historiador francés y la transmisión de su legado en el ámbito hispanoamericano.

1 De Michel de Certeau se han editado y traducido al español en México las obras: La escritura de la historia (1993); La fábula mística: siglos XVI-XVII (1982; 1994; 2006b); La toma de la palabra y otros escritos políticos (1995); La invención de lo cotidiano (1996; De Certeau, Giard y Mayol, 1999); Historia y psicoanálisis: entre ciencia y ficción (2003a); Una política de la lengua (2008), con Jaques Revel; La posesión de Loudun (2012). Sobre la vida y obra de Michel de Certeau, véanse Dosse (2003); Mendiola (2014) 
Joseph Moingt ingresó a la Compañía de Jesús en 1938 y defendió su tesis doctoral, sobre la teología trinitaria de Tertuliano, en 1955, bajo la dirección de Jean Daniélou. Profesor de la Facultad de Teología de Lyon, del Instituto Católico de París y del Centro Sèvres, también dirigió desde 1970 la prestigiosa revista Recherches de Science Religiuese, hasta 1997. El padre Moingt es considerado uno de los más importantes teólogos franceses del siglo XX. Es una referencia importante para los católicos de apertura, principalmente por su constante diálogo con la modernidad, que se expresa en sus numerosas publicaciones, entre las que destaca Croire quand même (2010).

\section{De La toma de la palabra a La fábula mística}

GUILLERMO AUGUSTO MÚNERA DUEÑAS Y GUILLERMO ZERMEÑO PADILLA (GM Y GZ): Padre Moingt, nos gustaría que nos hablara de la vida de Michel de Certeau. Ustedes compartieron muchas experiencias dentro de la Compañía y probablemente vivieron en la misma comunidad. Nos gustaría escuchar sus impresiones sobre el historiador francés, su conocimiento acerca de él, antes y después de ingresar a la Compañía de Jesús. Por otro lado, estamos interesados en conocer un poco más de la familia de Michel y del contexto histórico difícil que enmarca la producción de su obra.

JOSEPH MOINGT (JM): Michel de Certeau llega a la Compañía después de haber realizado su formación inicial en el Seminario Sulpiciano de Issy le Moulineaux. Un tiempo después, continúa sus estudios de formación en el Seminario Universitario de Lyon, donde conoce al padre jesuita Henri de Lubac. ${ }^{2}$ Estoy convencido de que el teólogo francés quedó maravillado con la sensibilidad y el encanto juvenil de Michel. Estoy seguro de que Michel encontró en Henri de Lubac una fuerte inspiración para ingresar a la Compañía de Jesús.
Quisiera remarcar que Michel ingresa a la Compañía en un momento de mucha dificultad para la Iglesia. Su ingreso a la Orden se desarrolla en contrasentido a la historia que se estaba produciendo dentro de la sociedad francesa y en un momento histórico en el cual la gran mayoría de los jóvenes querían dejar la institución. Es así como Michel, sobre todo a los ojos de Henri de Lubac, parecía un hombre que venía a defender la tradición de la Iglesia, sumergida en una crisis. Justamente, ese primer Michel de Certeau tradicional es el predilecto del actual papa Francisco, en particular cuando evoca al historiador francés como uno de sus teólogos preferidos. Creo que el papa sólo ha leído los primeros artículos del Certeau pío, publicados en la revista Christus (De Certeau, 1963; 1964a; 1964b; 1964c; 1965a; 1965b; 1966; 1970; 1973) así como la introducción a Pierre Favre (1960) y la Guide Spirituel de Jean-Joseph Surin (1963) establecida y presentada por De Certeau.

Michel de Certeau fue convocado por Maurice Giuliani para la fundación de la revista Christus. En ese espacio intelectual comenzamos a conocernos y a construir una amistad. También trabajé muchos años para la revista y era cercano de Giuliani. Por cierto, este último es una figura central dentro de la Compañía por su compromiso con la continuación de la tradición espiritual ignaciana. En este

Henri Sonier de Lubac, nació en Cambrai, Francia, el 20 de febrero de 1896, y murió en París, el 4 de septiembre de 1991. Fue un jesuita teólogo, cardenal francés y profesor de teología fundamental en la Facultad Católica de Lyon. En 1938, aparece su primer libro, Catholicisme, seguido de importantes obras, entre las cuales se encuentra Surnaturel (1946). En esta obra se determinó a estudiar, en el pensamiento cristiano, la relación entre lo natural y lo sobrenatural, con énfasis en la diferencia entre la doctrina tomista y el sistema de la naturaleza pura. Después de la publicación de esta obra, se le prohibió enseñar, en 1950. El padre Henri de Lubac fue rehabilitado en tiempos del Concilio Vaticano II y nombrado cardenal en 1983. 
contexto, Michel comienza a escribir sus primeros artículos, que me parece que se publicaron en una pequeña revista interna de la Universidad de Lyon.

Estos artículos sobre la mística fueron recuperados por Luce Giard y publicados en el libro La faiblesse de croire (De Certeau, 1987; 2003b; 2006a). Nunca estuve de acuerdo con la publicación de este texto. Me parece que Luce Giard mezcló muchos textos de diferentes épocas y da a entender a Michel de Certeau como un autor que jamás evolucionó en su pensamiento. Esto es totalmente contrario al espíritu de De Certeau. Si hay algo interesante en Michel es su capacidad de comprender que la tradición cambia todo el tiempo. Él me permitió entender que la tradición se transforma constantemente. Recuerdo mucho un día, cuando nos cruzamos en uno de los corredores de la comunidad y Michel me preguntó: “¿crees que la tradición nunca ha cambiado?”. En ese momento, mi respuesta no fue muy elaborada, sin embargo, su pregunta quedó grabada con fuerza en mi espíritu.

Michel tenía muy claro que no es sólo el presente o el futuro lo que nos hace cambiar. Hay que considerar siempre el pasado que nos habita, incluso el pasado que rechazamos. Éste siempre está con nosotros, vive con nosotros. En mi universo teológico, todo ello me ha hecho comprender de una manera diferente la tradición de la Iglesia, que comienza a principios del siglo III, cuando es consagrado el primer obispo, y podemos encontrar la obra clásica de Hipólito sobre la tradición. Se podría pensar que la tradición de la Iglesia se separó por completo de la tradición apostólica, es decir, de la enseñanza de la tradición de Cristo y los Apóstoles durante los primeros dos siglos. Sin embargo, quisiera subrayar que esta tradición estuvo también habitada por la tradición apostólica. Es así como logré comprender, y me esfuerzo por mostrar que se puede recuperar la tradición apostólica dentro de la tradición de la Iglesia. En otras palabras, mis esfuerzos no consisten en mostrar que la tradición de la
Iglesia se ha desviado de la tradición apostólica, sino que dentro de la tradición de la Iglesia podemos recuperar la tradición apostólica que se creía perdida. En ese sentido, los archivos nos permiten hacer una interpretación para comprender, en medio de los desvíos de la tradición de la Iglesia, la presencia de la tradición apostólica. Esta lectura crítica de renovación constante de la historia se la debo a Michel de Certeau. Siempre he admirado las técnicas que ustedes los historiadores utilizan y la relación con el trabajo de archivo. De hecho, Michel siempre fue un hombre de archivo. Recuerdo mucho su intenso trabajo de archivo en Bordeaux, cuando preparaba uno de los capítulos de La fable mystique (De Certeau, 1982; 1994; 2006b) sobre el santo de Aquitania. Su seriedad en los archivos era una de sus principales características y creo que por eso se impuso, claro está, no sin muchas reticencias a sus trabajos, por ser innovadores.

Esa misma característica de innovación la transmitía a sus estudiantes. Uno de sus discípulos, profesor de la Universidad de Nantes, especialista en la antigüedad clásica, siempre afirmaba haber aprendido de Michel la importancia de "traicionar a su maestro" y "matar al padre". Este legado nos ayuda a entender que la historia debe continuar de la misma manera. Todo historiador debe separarse de su predecesor, debe alejarse para avanzar, sin permanecer prisionero de las ideologías del pasado y recordar al mismo tiempo la herencia de su maestro. Al respecto, también tengo una enorme deuda intelectual con Michel. Me enseñó acerca de la historia y la manera como se hace.

Respecto a la familia de Michel, tuve la oportunidad de conocerla durante su primera época, es decir, cuando Michel se encontraba en dilema ante las autoridades de la Compañía. Utilizo la palabra dilema y no oposición. Siento que es mucho más precisa, puesto que nunca sentí a Michel en oposición a la Orden. Fui invitado a predicar un retiro espiritual a unas religiosas que vivían en Chambery y 
Michel le pidió amablemente a su padre ocuparse de mí durante esos días. Tuve la oportunidad de conocer a su familia, conversar con sus padres y conocer su entorno familiar. La casa de sus padres era un pequeño castillo, ubicado a unos $10 \mathrm{~km}$ del centro de la ciudad. Su familia pertenecía a una pequeña burguesía de provincia que conservaba las costumbres clásicas de su cultura. Me parece que las costumbres de Michel, respecto a su familia, fueron cambiando en medio de un proceso de inquietudes. La relación con su madre fue muy cercana y su muerte le produjo un gran dolor.

La madre de Michel murió víctima de un accidente automovilístico en el que Michel perdió la vista de un ojo y ese acontecimiento doloroso afectó la relación con su padre, que conducía el automóvil. Esta relación de tensión con su padre se acrecentó cuando Michel pronunció su famoso discurso sobre mayo del $68 .{ }^{3}$ En su interpretación dada a un periodista, en 1974, toma una posición pública y legitima la revuelta de los estudiantes, de la sociedad. Supongo que para los medios católicos tradicionales que frecuentaban De Certeau y su familia, su toma de posición pública no fue fácil. Para ese entonces $\mathrm{Mi}$ chel tenía a cargo varios estudiantes católicos con los que se reunía cerca de Dijon y también compartía con algunos alumnos del padre Daniélou, responsable del acompañamiento pastoral de las señoritas de la Escuela Normal Superior.

Sus análisis del 68 se relacionaban con la crisis que se vivía en la sociedad francesa de su momento y en la que la recomposición del catolicismo era clara. Los seminarios se desocupaban desde Canadá hasta Holanda. Sus análisis describían muy bien esta crisis y presentaban con claridad el fenómeno de la folclorización de la religión. Me parece también que comprendió con rapidez las positividades que se encuentran dentro de la religión, como lo enuncia Hegel. Al respecto, los milagros, las instituciones, las devociones, en ocasiones terminan ocultando el mensaje fundamental de la Iglesia, sin que ésta se percate de la crisis por su deseo de mantenerse vigente dentro de la sociedad. En mi opinión, hay que tener mucho cuidado con esta actitud de la Iglesia. En efecto, se puede atraer mucha gente, pero de un momento a otro, la fe desaparece, se vacía del interior.

Por mi parte, estoy analizando este fenómeno en un libro que publicaré y que tratará de examinar el principio del siglo XX. Durante este periodo podemos observar una generación de intelectuales católicos brillantes, grandes profesores cristianos y grandes críticos. Sin embargo, la Iglesia católica, en medio de tanta lucidez intelectual, no fue capaz de asumir una racionalidad crítica. Esta racionalidad crítica de la que hablo es la encargada de combatir las positividades mencionadas por Hegel y de las que Michel se ocupó en sus análisis. Los milagros y todo aquello que se relaciona con el "hacer creer" eran los temas predilectos de Michel de Certeau. Por mi parte, me asombra observar cómo la Iglesia continúa imponiéndose con los milagros y demás positividades que no se ponen en duda. Hoy en día, ningún historiador sensato afirmaría la autoridad de Moisés, puesto que su existencia misma ha sido puesta en duda. Bajo este mismo espíritu de racionalidad crítica, es necesario tratar la revelación del Antiguo Testamento, la revelación del monte Sinaí y las demás positividades.

En el número de junio-julio de Études, Michel de Certeau (1968) analizó los acontecimientos ocurridos en mayo de 1968. En compañía de Bruno Ribes, director de la revista, los dos jesuitas se dirigieron en febrero de 1968 al campus de la Universidad de Nanterre para encontrarse con los líderes estudiantiles e intentar comprender las primeras manifestaciones de crisis que se producían en la sociedad. Como resultado de estos encuentros, se publicó un artículo de Michel que inmortalizó una de sus frases: "en mayo pasado, se ha tomado la palabra como se ha tomado la Bastilla en 1789". Esta sentencia fue citada en varias oportunidades, en especial por Edgar Faure y Georges Pompidou. Véase De Certeau (1995). 
Estas críticas deben ser llevadas incluso al nacimiento mismo del cristianismo. Muchos de los modernistas, algunos de ellos cristianos convencidos, han querido construir un estudio científico del problema, no por ello tienen el propósito de destruir a la Iglesia. Nuestros intereses han estado también enfocados en comprender la composición de los Evangelios y denunciar las contradicciones que pueden producirse entre unos y otros, al mostrar también las pocas bases científicas e históricas sobre las cuales la Iglesia se ha construido, una de ellas, la maternidad virginal de María. Al respecto, hay sólo dos Evangelios de cuatro que tocan este tema.

Me parece que la Iglesia, con el apoyo de la burguesía, no ha querido tratar estas peguntas ni reformular la transmisión de esta tradición. Es gracioso observar que en ocasiones las personas se sostienen con estas versiones menos sólidas y menos claras de la revelación. Éste es el panorama en el que nos encontramos dentro de la Iglesia y del cual no hemos logrado salir.

Pienso que Michel de Certeau no tenía un interés particular en llevar estos debates al interior de la Iglesia. Ha podido hacerlo, como lo hicieron varios de sus amigos, en particular el dominico Claude Geffré, ${ }^{4}$ con quien se formó en el seminario de Issy les Moulineaux. Me parece que su posición intelectual no era contra la Iglesia ni contra la fe. Ayudó en términos intelectuales a un gran número de escuelas de teólogos, de religiosos de diversas nacionalidades, sobre todo franceses e italianos. Tuvo un papel representativo en las configuraciones intelectuales de los jóvenes de la Sorbona, de algunos teólogos y de los jóvenes historiadores, por eso me parece importante precisar que su pensamiento no estaba en contra de la fe. Cuando trataba temas de la Iglesia, también intentaba presentar cómo ésta había introducido reflexiones críticas al respecto. De igual forma, su lenguaje, en ocasiones provocador, como lo vemos en el título de La fable mystique (De Certaeau, 1982; 1994; 2006b), no tenía una pretensión peyorativa. Por el contrario, cuando se refería a $\mathrm{La}$ fable mystique, hablaba de la posibilidad de hacer hablar de ello. Ante todo, sus trabajos se orientaban por un espíritu crítico, con un amplio conocimiento de los temas que estudiaba, como en el caso de la mística en el siglo XVII y las preguntas que le surgían al aproximarse a este universo.

De igual forma, su espíritu crítico lo llevó constantemente a introducir nuevas técnicas y análisis en el estudio de la mística. Por ejemplo, en sus lecturas clínicas, psicológicas y psicoanalíticas de la mística. Allí vemos que hace entrar con fuerza el psicoanálisis como instrumento de análisis histórico. Me parece que su actitud hizo explotar la crítica histórica al introducir nuevos estados de factores, elementos que están presentes en la escritura de la historia: la ruptura instauradora.

\section{Henri de Lubac y Michel de Certeau: entre la Nouvelle théologie y la historia}

GM y GZ: Michel de Certeau sufrió mucho por la ruptura radical con su maestro Henri de Lubac. Siempre trató de acercarse, pero el teólogo nunca se lo permitió.

JM: Cuando Henri de Lubac conoció a Michel, tenía mucha confianza en la inteligencia del joven jesuita para continuar trabajando sobre la mística de la Compañía. Sin embargo, uno podía percibir de inmediato que tenían dos temperamentos y formas

4

Claude Geffré (1926-2017) fue uno de los teólogos dominicos más importantes que participó de manera activa en la renovación del pensamiento católico después del Concilio Vaticano II, identificado con dos ejes mayores en teología: el giro hermenéutico y el pluralismo religioso. Profesor de teología fundamental en el Instituto Católico de París desde 1965, Geffré dio un giro a sus reflexiones al introducir la hermenéutica y considerar la imposibilidad del teólogo de concentrar sus trabajos en la defensa de los dogmas. 
de proceder totalmente distintos. Por mi parte, frecuentaba mucho al padre De Lubac, hasta que mi forma de pensar no le gustó y me excluyó también de sus discípulos. Él tenía un temperamento muy difícil. Jamás tuve la oportunidad de mantener una discusión teológica seria con él. Los únicos temas que admitía eran sus historias de las reuniones con los dominicos, los jesuitas, los obispos y los jerarcas de la Iglesia. Le gustaba mucho conversar de sus dificultades con los demás, entre ellas, siempre pensó que el Concilio Vaticano II se había convocado para condenarlo y hablar de él.

Ahora bien, para volver al tema del legado de Michel, siento que su huella es mucho más fuerte en los jóvenes historiadores que dentro de la misma Iglesia. Si bien no conozco a las nuevas generaciones de teólogos, en mi época no era muy bien recibido en los círculos eclesiásticos. Lastimosamente, murió muy joven, es claro que Michel tenía un largo camino de producciones intelectuales con todo el material que había acumulado en sus viajes y en los archivos. Michel hubiera podido escribir muchas obras. Disponía de mucho material que había recuperado en varios lugares, mucha bibliografía, referencias. Siempre contaba con nuevas propuestas de investigación. Era un hombre admirable, incluso en la manera en que asumió su enfermedad y la tranquilidad en los últimos días de su vida.

GM y GZ: ¿Por qué no dejó la Compañía?

JM: Lo primero que quisiera decir es que nunca me atreví a preguntarle a Michel sobre este asunto. $\mathrm{Hu}-$ biera sido, de mi parte, creer que él estaba mejor fuera de la Compañía, pensamiento que nunca pasó por mi cabeza. Siempre lo consideré un jesuita extraordinario. Tampoco hubiera pasado por mi cabeza hacerle una pregunta que le molestara. Recuerdo varios casos de jesuitas amigos que dejaron la Compañía durante esta misma época difícil. El procedimiento era escribir al general para solicitar las dimisorias. Jamás escuché de una carta o un procedimiento parecido de su parte. Sin embargo, muchos de mis compañeros jesuitas pensaban lo contrario. Algunos no veían con buenos ojos sus viajes constantes ni sus proyectos. Entenderlo no es fácil, su pensamiento es complejo e incluso ha sido objeto de falsas interpretaciones por la dificultad de su obra. No creo tampoco que su escritura sea difícil o que su propósito sea confundir. Por mi parte, considero que su razón principal para permanecer como jesuita era su amor y fidelidad profunda a la Compañía. Pienso que fue un hombre que jamás deseó dejar la Orden.

GM y GZ: ¿Cuáles considera usted que son las diferencias entre Michel de Certeau y Henri de Lubac respecto a la historia?

JM: Uno de los puntos centrales de la discusión con Henri de Lubac es la teología de los padres y la tradición. En este punto entran los problemas relacionados con la interpretación de los dogmas y la filosofía.

Ahora, respecto a Michel, hay varios puntos centrales de diferencia. En él encontramos un pensador que está en movimiento constante, reinterpretando, escapándose a la escolástica. En las comprensiones de los padres de la Iglesia de Henri de Lubac no hay una lectura crítica de la historia. En Michel, la historia está en constante movimiento, en constante cambio, hay que reconocer las variaciones. En este aspecto, me parece que Michel superó rápidamente a Henri de Lubac. De igual forma, Michel no buscaba fijarse en una sola línea de pensamiento y sus trabajos estaban cargados de nuevas teorías e interpretaciones. Tampoco tenía una conciencia de maestro para formar discípulos. Trabajaba con mucha libertad con sus alumnos y se transformaba con ellos. Por el contrario, Henri de Lubac era una persona que siempre tuvo una visión de sí mismo como maestro. Por eso desconoció a Michel cuando ya no lo sintió más su discípulo. Sin embargo, la actitud de Michel nunca 
cambió. Siempre tuvo un gran respeto por De Lubac y siempre lo consideró su maestro, hasta el día de su muerte. De Certeau comprendió muy bien que la herencia de su maestro lo habitaba, aun sabiendo que sus reflexiones estaban encaminadas hacia otros lugares. Esta herencia del padre De Lubac es clara en todos los estudios realizados por Michel sobre la mística de la Compañía.

Uno de los libros más famosos de De Lubac, Catolicismo (1938), mostraba en un primer momento una apertura al mundo moderno. Sin embargo, seguía pensando en el humanismo como ateo. Era un hombre que tenía miedo de la palabra "apertura”. Para él, mencionar esta palabra significaba una relación directa con el marxismo, con el ateísmo, y consideraba que era precipitar a la Iglesia, como se lo hizo saber al cardenal Marty, arzobispo de París.

GM y GZ: ¿Cuál fue su relación con Henri de Lubac? JM: Mi relación con el padre De Lubac no fue fácil. Muy pronto abandoné en París el pensamiento tradicional de la Iglesia. La filosofía moderna y las lecturas de Heidegger y Merleau Ponty me condujeron a nuevas comprensiones de la tradición y el cristianismo. Nuestras comprensiones del dogma no eran las mismas. Sin embargo, nunca tuve la oportunidad de discutir con él sobre ello. Siempre consideré que era un hombre con una gran cultura, pero con horizontes filosóficos muy pobres. Nunca aceptaba que el pensamiento podía cambiar y tenía muchas dificultades para estudiar a los autores y sus reflexiones dentro de un contexto. Por ejemplo, en sus reflexiones sobre los padres de la Iglesia, no supo reconocer la importancia de Erasmo y sus lecturas sobre los padres.

Ahora bien, como ustedes me preguntan por la Nouvelle théologie, me parece importante precisar que esta teología, nacida en Fourvière y llamada así por el padre dominico Réginald GarrigouLagrange (1877-1964), sí posee elementos nuevos respecto a otras teologías. Es nueva en la medida en que desplazó la reflexión teológica que se centraba en la teología escolástica hacia la teología de los padres de la Iglesia. En este caso, hacía un voto de libertad y permitía otras reflexiones, claro está, sin profundizar en algunas cuestiones delicadas, como el problema del dogma. La ventaja de la teología de los padres era que no estaba fija en ciertas teorías filosóficas propias del tomismo, en el que se había englobado toda la teología cristiana. Fue así como la teología romana había sacado el tomismo de la historia, para construir un pensamiento teológico eterno.

Esta Nouvelle théologie permitía un poco más de flexibilidad a los teólogos. Los especialistas de la escolástica habían formalizado los dogmas bajo una sola interpretación que conducía a una enseñanza invariable de éstos. Al respecto, la Nouvelle théologie era mucho más flexible frente a sus fuentes y paradigmas reguladores. Sin embargo, sus comprensiones frente a los dogmas no cambiaban y los seguía pensando desde una tradición interna. Es cierto que yo me acerqué a la Nouvelle théologie, sin permanecer en ella, en búsqueda de un poco más de libertad en la interpretación. Acercarme al pensamiento de los padres de la Iglesia me permitió una mayor libertad para repensar la tradición y todas las reflexiones posteriores a la escolástica, es decir, la filosofía idealista y crítica.

Respecto a Michel de Certeau, no creo que fuera partidario de esta teología que representaba su maestro Henri de Lubac. Para De Certeau, la historia se encuentra en constante movimiento e interpretación, al contrario de las reflexiones del padre De Lubac. Este último tenía la tendencia de hacer otra escolástica y de tomar la tradición como una continuación del pensamiento, en efecto, con algunas variantes, pero mínimas. Su lectura de la historia de los padres de la Iglesia estaba construida por la continuidad, sin variaciones.

En el pensamiento de Michel encontramos un espíritu contrario. La historia cambia de acuerdo 
con la civilización, la cultura, el estado social, el estado político en el cual uno vive y todo ello introduce variaciones considerables en la lectura de la tradición. Es allí donde se encuentra la ruptura entre los dos. Henri de Lubac tuvo la impresión de haber perdido su tiempo y energía con Michel y ya no reconocía en el historiador a uno de sus discípulos al verse superado. Henri tenía una conciencia de sentirse siempre el maestro y estar presente en la vida de sus discípulos. Michel nunca pensó de esta manera. Sus alumnos fueron coproductores de su pensamiento y le ayudaban a incorporar nuevas herramientas a sus investigaciones. De igual forma, nunca se cerró a aceptar nuevas teorías que comenzaban a ser desarrolladas en su época, como es el caso de la lingüística, el psicoanálisis, entre otras. Es posible que Michel desconcertara por este deseo de no querer fijarse en un solo lugar y respetar a la vez el lugar de los otros.

GM Y GZ: ¿Cree usted que sus producciones intelectuales transformaron las producciones intelectuales de Michel y viceversa?

JM: No podría responder con mucha seguridad a esta pregunta. No podría decirles que mis producciones intelectuales le ayudaron a Michel. Sin embargo, siento que hay varios puntos centrales en los cuales nos identificamos. Uno de estos puntos, que quisiera resaltar, es la actitud de no querer tener discípulos. En mi caso, tenía muchos estudiantes a cargo durante mi época de profesor en el seminario y en la universidad. Siempre tuve una actitud de aprendizaje de mis alumnos. En ocasiones les aconsejaba leer libros que no había leído y que me obligaban a

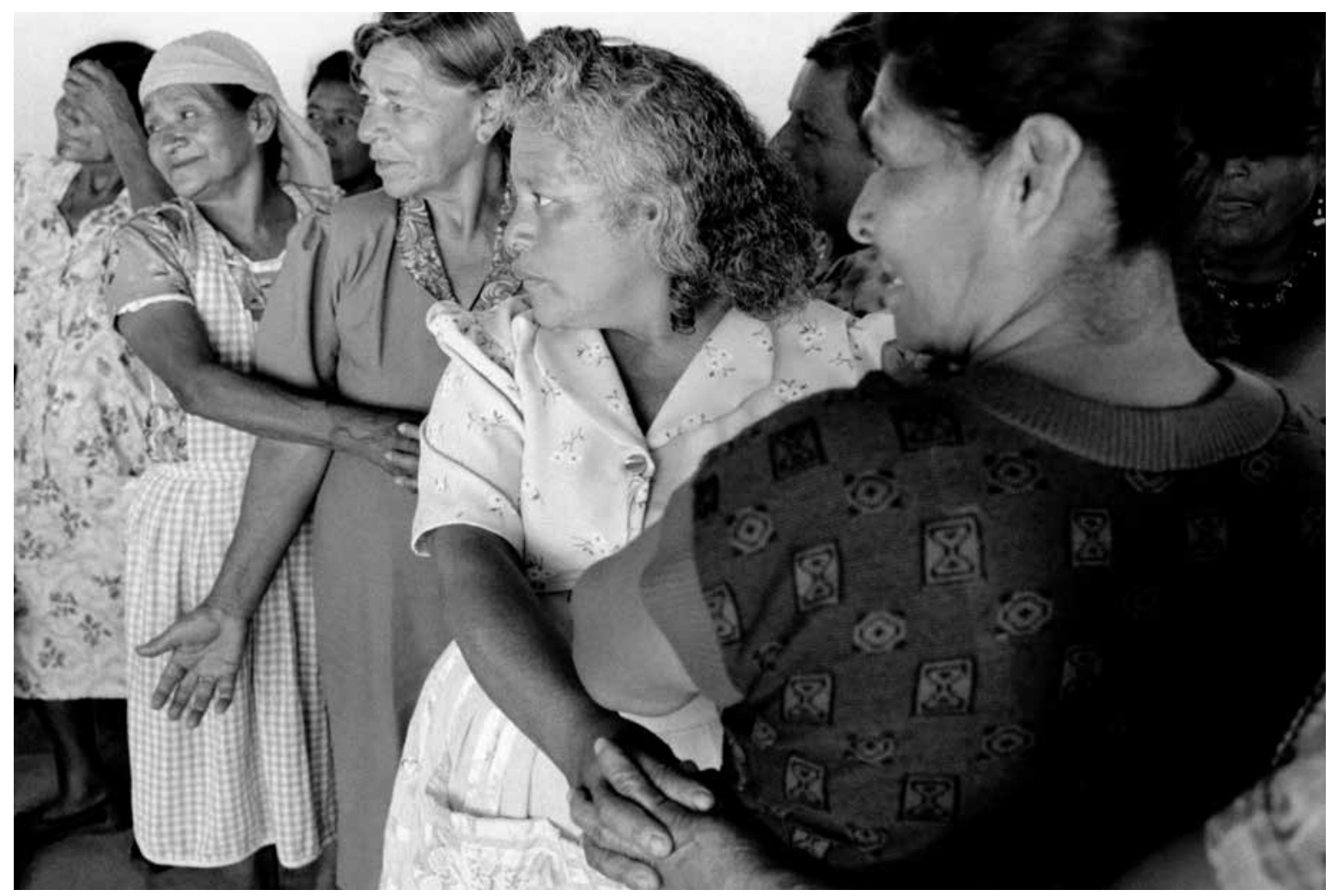

Ricardo Ramirez Arriola • Parteras, San Pedro Pinula, Jalapa, Guatemala, 2000. 
incursionar en nuevos campos del conocimiento. Esta actitud me ayudó a entender que uno crece intelectualmente con los otros, de manera conjunta.

Por otro lado, siempre compartí las intuiciones de Michel sobre la interpretación del pasado. La historia cambia con sus intérpretes. En el caso de Henri de Lubac, me parece que no comprendió nuestra manera de pensar. Siempre creyó que la dialéctica buscaba evacuar el pasado, sin que esto fuera verdad. Michel siempre afirmaba que estamos habitados por el pasado, incluso más de lo que podemos pensarlo. Este pasado que portamos en nosotros mismos es siempre una fuente de descubrimiento en la medida en que no lo fijemos a todo precio en una escuela, ideología o libro. De Lubac, al referirse al pensamiento dialéctico, pensaba inmediatamente en el olvido del pasado y nos identificaba a Michel y a mi dentro de esa dinámica. Tal vez nunca comprendió que Michel siempre lo consideró su maestro y siempre le llamaba así. No por halagarlo, sino por la conciencia profunda de estar habitado por el pensamiento de De Lubac, y al mismo tiempo, haberlo superado. Es claro que el interés de Michel por la mística era herencia del padre De Lubac, quien lo había orientado en este camino al ingresar en la Orden. Sin embargo, Michel muy pronto tomó un camino distinto en sus trabajos sobre la mística, como en el caso del santo de Bordeaux y los místicos de la Compañía convertidos a la espiritualidad de Teresa de Ávila, que no estaban anclados al pensamiento de los antiguos místicos de las primeras espiritualidades, como por ejemplo, del padre Orígenes [Alejandría, 185 d C-Cesarea Marítima 254 d. C.]. Me parece que De Lubac no entendió estas nuevas comprensiones de Michel.

Para volver a Henri de Lubac, es curioso que su libro Catholicisme (1938), muy conocido en diversos círculos franceses, intentara una apertura con el pensamiento moderno. Sin embargo, su interés por el humanismo del siglo XVII lo llevó rápidamente a identificarlo como ateo. Recuerdo que cuando llegó el Concilio, junto con la necesidad de abrirse al mundo moderno, Henri de Lubac juzgó esta apertura como un proyecto marxista y ateo. Sobre este punto, recuerdo su problema con el cardenal Marty, arzobispo de París, quien había asumido bajo el espíritu del Concilio una apertura al mundo moderno que el padre De Lubac veía con malos ojos y juzgaba como una precipitación de la Iglesia al marxismo. El cardenal Marty, más de una vez me confesó que no entendía los juicios del padre De Lubac ni su visión del mundo.

GM y GZ: ¿Cuáles fueron las razones principales de su ruptura con Henri de Lubac?

JM: Un primer elemento concierne a la incomprensión del padre De Lubac de mi formación hegeliana. Siempre consideró que yo debía permanecer enseñando en Fourvière, en especial la doctrina social de la Iglesia. Eso le confirmaba que yo no estaba perdido. Sin embargo, cuando fui enviado a París, el contexto me desbordó y ya no podía continuar enseñando de la misma manera. Muchas de las personas que frecuentaban mis clases no sabían griego y eso no me permitía utilizar las mismas herramientas. Por otro lado, el público que comenzaba a frecuentar mis seminarios en París era muy exigente, tenía un amplio conocimiento en teología moderna y estaban formados bajo el espíritu crítico de los teólogos protestantes, como es el caso de Moltmann. De inmediato, el padre De Lubac estuvo en desacuerdo con esta nueva forma de pensamiento. Creía que las lecturas de Moltmann y los círculos intelectuales protestantes podían llevar al abandono del pensamiento tradicional de la Iglesia. Poco a poco continué con estas nuevas reflexiones críticas y abrí mi pensamiento a otras reflexiones, como las de Heidegger y Merleau Ponty. Estos autores, junto con el pensamiento moderno, me permitieron cambiar las comprensiones del dogma, como era visto por la escolástica. En ese punto, el padre De Lubac creía que yo estaba a punto de abandonar la 
fe y rechazó de manera radical volver a saludarme y dirigirme la palabra. Me hizo lo mismo que a Michel de Certeau.

Nunca tuvimos la oportunidad de conciliar. El padre De Lubac no aceptaba discutir conmigo, de hecho, era un hombre que no sabía discutir. Estaba acostumbrado a exponer sus ideas y ser escuchado, pero jamás a discutir. Siempre me pareció un hombre con una cultura general increíble, pero con horizontes filosóficos muy pobres. Sus producciones intelectuales siempre intentaban recuperar la continuidad de la fe y leía los textos del siglo III y XII de la misma manera, sin percibir las diferencias de los contextos. Sus lecturas, siempre atentas a recuperar la continuidad, olvidaban las preocupaciones por los contextos y las rupturas.

Cuando comencé mis estudios sobre los padres de la Iglesia, en especial los textos de Tertuliano para mi tesis, comprendí la necesidad de entender la cultura y el contexto del autor. Al principio, pensé que una lectura de sus textos me bastaría para hacer un buen trabajo y comprender el problema de la divinidad y las tres personas en el pensamiento de Tertuliano. Este trabajo implicó un análisis considerable de diferentes conceptos, entre ellos la sustancia y la persona, que no significaban lo mismo uno o dos siglos más adelante. Este ejercicio me obligó a renunciar a una cierta concepción de pensamiento universal de los conceptos. Es necesario estudiar a los autores en su contexto, entender su historia. En este punto, Henri de Lubac no era preciso. Siempre consideró a la Iglesia como un dechado de virtudes, sin admitir los principados, el nepotismo, los problemas de dinero.

GM y GZ: ¿Cuál es su opinión sobre la transmisión de la obra de Michel de Certeau y su posible proceso de beatificación?

JM: El primer elemento que debo mencionar es mi desacuerdo con Luce Giard y la forma en que condensó los textos. Hablo en particular del libro
La faiblesse de croire (De Certeau, 1987; 2003b; 2006a). ${ }^{5}$ No logro comprender cómo el espíritu de una historiadora pudo juntar estos textos que se encontraban separados por más de diez años y poseen diferencias considerables. Encontramos textos de Michel de Certeau, teólogo pío, unidos con escritos de mayo del 68, momento de crisis en el que los seminarios se desocupaban. Esa presentación de los escritos me parece que cambia el sentido y no permite ver la evolución del autor, lo presenta en continuidad, sin mostrar su evolución. Presentar la obra de Michel de esta manera puede dar la impresión de estar frente a un teólogo clásico y pío. A mi parecer, es cortarle la cabeza al autor, no ser capaz de comprenderlo como un caminante, un hombre de rupturas.

Por mi parte, tengo miedo de que se quiera proyectar esa imagen de Michel al mostrarlo como un autor de continuidad con el propósito de su beatificación. Este reagrupamiento de textos otorga otro sentido y no permite ver la evolución del pensamiento de Michel de Certeau. No digo esto por criticar a Michel, por el contrario, me parece importante rescatar su capacidad de evolución y de introducir nuevas preguntas entre una época y otra.

Ahora, respecto a un posible proceso de beatificación no sé qué significa eso en nuestra época. Hoy todos los papas beatifican a diestra y siniestra. Si eso ocurriera, se nos obligaría a entender a Michel como un teólogo clásico y esto para mí es inaceptable. Eso significaría cortarle la cabeza a un gran pensador, disminuirlo. Pienso que hay que comprender a Michel como alguien cambiante, justo eso es lo admirable de este historiador. Estoy de acuerdo con que hay continuidades, sobre todo en el tema de la mística, sin embargo, esas continuidades

5

Reúne textos escritos entre 1964 y 1983, sobre la tradición cristiana y lo que hace la fe, la crisis de la autoridad religiosa y la Iglesia. 
pasan también por las rupturas. Me parece que Luce Giard intenta borrar las rupturas, no quiere destacarlas. Por mi parte, no estaba de acuerdo con que hiciera un segundo tomo de La faible mystique y agradezco mucho su renuncia a este proyecto. Creo que finalmente se contentó con lo que Michel había previsto.

GM Y GZ: ¿Encuentra usted una relación entre el pensamiento de Daniélou, De Certeau y De Lubac? JM: Por mi parte, podría hablar un poco más de la relación entre Henri de Lubac y Daniélou. ${ }^{6}$ Esta relación entre los dos jesuitas comienza con la fundación de la revista Sources Chrétiennes. Sin embargo, no se puede decir que tuvieran una gran amistad. El padre De Lubac siempre encontró a Daniélou como un hombre mundano y sus relaciones se limitaban al trabajo en común sobre la colección.

Mi percepción de Daniélou siempre fue la de un hombre institucional. Al igual que Henri de Lubac, los dos siempre buscaron hacer una bella carrera eclesiástica. Sin embargo, Daniélou era mucho más conocido y le gustaba frecuentar grandes personalidades eclesiásticas y civiles. Por otro lado, también fue identificado con la Nouvelle théologie de Fourvière, tal vez por su interés en Orígenes y su obra. Si bien la palabra "nueva" en la Nouvelle théologie no le simpatizaba mucho a De Lubac, pienso que Daniélou la aceptó con agrado y no le molestó. Para profundizar en esta relación habría que consultar los archivos de Henri de Lubac. Cuando fui director de Sciences Religieuses guardé muchas de sus cartas y documentos. No sé en dónde se encuentren en este momento y me temo también que muchos debieron salir del dominio de la Compañía cuando De Lubac fue nombrado cardenal.

De Lubac me hablaba de Daniélou como alguien que lo vigilaba. Sentía que no estaba de acuerdo con él. Daniélou era más mundano, político, un decano, leía rápido. Yo debía corregirle sus textos para publicar, yo le decía: "padre, lo que usted escribe es contrario a las tesis del autor". Él se sorprendía y me pedía que arreglara sus escritos. Al respecto, ni Daniélou ni De Lubac alcanzaban un nivel elevado entre los intelectuales parisinos, sobre todo los especialistas en padres de la Iglesia, que tenían posturas distintas y que los dos jesuitas no admitían con facilidad. Me parece que entre De Lubac y Daniélou había colaboración, trabajo, pero no una verdadera comunidad intelectual. Ésa es mi interpretación de estos dos personajes. No puedo decir mucho de la relación entre Daniélou y De Certeau. Creo que no hubo una relación intelectual.

GM y GZ: ¿Usted cree que hubo una relación intelectual recíproca entre Michel de Certeau y la Compañía?

JM: Me parece que un momento importante, que pudo marcar a Michel de Certeau, fue la relación con Maurice Giuliani y la revista Christus. Este jesuita fue también un hombre de archivo, con un interés particular por recuperar la tradición espiritual de la Compañía. Creo que Michel tenía ese mismo interés por la mística y la tradición espiritual de la Orden. Sin embargo, sí hubo en medio de la recuperación de esta tradición un clima polémico, en particular en sus estudios sobre el santo de

6

Jean Daniélou nació en Neuilly-sur-Seine, Francia, el 14 de mayo de 1905, y murió en París, el 20 de mayo de 1974. Fue un jesuita, teólogo y cardenal francés identificado con la Nouvelle théologie y reconocido en el mundo por su participación en el Concilio Vaticano II (1962-1965). Fundador de la revista Sources Chrétiennes junto con Henri de Lubac, el padre Daniélou es también conocido por la renovación de la patrística católica. En 1944, ingresó al Instituto Católico de París como responsable de la cátedra de historia del cristianismo antiguo y fue nombrado decano de la Facultad de Teología en 1962. Es autor de varias obras sobre la historia de los padres de la Iglesia, entre las más representativas se encuentran: Origène (1948); Sacramentum futuri. Études sur les origines de la typologie biblique (1950); Bible et liturgie, la théologie biblique des sacrements et des fêtes d'après les Pères de l'Église (1951). 
Bordeaux. De Certeau rescató las polémicas en el interior de la Compañía sobre estos santos jesuitas que habían sido nutridos de la teología carmelita. Eso era nuevo respecto a la mística de la Compañía y Roma los había acusado de alejarse de la tradición. Por el contrario, Michel de Certeau los restableció dentro de la tradición mística jesuítica, mostró las diferentes corrientes de interpretación y las diversas historias que podían converger dentro de la Compañía. No creo que esto le gustara a Henri de Lubac, que prefería la convergencia. Él quería borrar las diferencias, actuaba bajo los preceptos de la exégesis antigua y olvidaba las propuestas de la exégesis moderna y su interés por las diferencias y las rupturas. Michel nos permitió pensar en la Compañía de otra manera y entender que no hay sólo una espiritualidad en ella, sino varias.

GM Y GZ: ¿Encuentra usted una relación entre las producciones intelectuales de Michel de Certeau y los dominicos?

JM: Para hacer la genealogía, me parece importante mencionar la amistad de Michel de Certeau con Claude Geffré. Ellos fueron condiscípulos en el seminario de Issy les Moulineaux. Hay que rescatar también que Claude Geffré fue un gran teólogo y tenía un espíritu de apertura muy grande. Fue también un gran especialista de los teólogos y pensadores modernos. Recuerdo que, cuando llegué al Instituto Católico de París, era uno de los teólogos que mejor conocía la filosofía y el pensamiento moderno. Tuve que hacer un gran esfuerzo para alcanzarlo.

Sin embargo, Geffré y yo siempre mantuvimos una gran diferencia. Él quería que yo tratara temas relacionados con las relaciones entre religiones. Sin embargo, siempre argumenté que para mí una sola religión ya implicaba mucho trabajo. El padre Geffré conocía mis opiniones al respecto y las respetaba. Por mi parte, nunca le reproché los peligros desde el punto de vista de la ortodoxia, sabiendo que teníamos puntos dispares sobre la búsqueda de un fundamento en común entre todas las religiones. Por mi parte, prefería trabajar el ecumenismo entre las religiones cristianas y por ello decidí profundizar en el pensamiento protestante, en particular en Barth y Moltmann, entre otros. Respecto a Michel de Certeau, creo que continuaron su amistad. Me parece que Claude Geffré tuvo una apertura al pensamiento de De Certeau y su pensamiento lo marcó.

Ahora bien, respecto a una reciprocidad, no podría afirmarlo. Claude Geffré, aunque era un hombre abierto, siempre permaneció produciendo desde un punto de vista muy eclesiástico. Me parece que buscaba un ecumenismo doctrinal. Por el contrario, Michel vio rápidamente que las religiones son verdaderas en el folclor. Este historiador comprendió, como yo lo comprendí también más tarde, que la religión es social antes de ser una doctrina o un pensamiento. Este último punto lo comprendí gracias a Michel.

Por último, creo que un dominico importante para el pensamiento de Michel de Certeau fue el padre Chenu. ${ }^{7}$ Este gran teólogo fue muy sensible a la

7 Marie-Dominique Chenu nació en Soisy-sur-Seine, Francia, el 7 de enero de 1895, y murió en París, el 11 de febrero de 1990. Fue uno de los teólogos más importantes del siglo Xx, conocido principalmente por su apoyo al movimiento de los curas obreros, sus aportes a la renovación del tomismo y su participación como experto en el Concilio Vaticano II (1962-1965). En 1920, sustentó su tesis doctoral bajo la dirección del dominico Garrigou-Lagrange. Como profesor de la Escuela de Saulchoir, se convirtió rápidamente en un reformador del pensamiento de santo Tomás e introdujo el método histórico en la reflexión teológica. En 1942, su libro Une école de théologie: le Saulchoir? fue sancionado por Roma. Con Yves Congar, teólogo dominico, fue de nuevo sancionado en la década de 1950 por respaldar el movimiento de los curas obreros. En la década de 1980, Chenu apoyó el movimiento de la teología de la liberación, en particular la obra de Gustavo Gutiérrez, considerada por el dominico un ejemplo eminente de la Nouvelle théologie. 
historia y creo que Michel siempre tuvo un interés particular en la Escuela de Saulchoir.

GM y GZ: ¿Cree usted que hubo un interés particular de Michel de Certeau por la filosofía de Hegel y algunas obras de Marx?

JM: No lo creo. Me parece que Michel no continuó con la lectura de estos autores. Me parece que sus estudios sobre la mística lo hicieron pasar a nuevas reflexiones y descubrir nuevas corrientes de pensamiento, entre ellas, Heidegger y Freud. Al contrario de mi proceso, no creo que Michel haya continuado con la lectura de Hegel, mucho menos con Marx. Es verdad que hubo una generación de jesuitas que se interesaron por Marx, entre ellos el padre Calvez; sin embargo, Michel era un hombre que estaba todo el tiempo innovando. Tampoco tenía mucha necesidad de continuar con algunas lecturas. Era un hombre con una capacidad extraordinaria de asimilar autores y obras, lo que le permitía pasar con rapidez a nuevas tendencias. Tenía una gran avidez por la novedad y creo que por eso viajaba tanto, sobre todo a Italia, tratando siempre de construir puentes. De ahí también su interés por la literatura y las novelas, y su capacidad de dar a conocer a los autores en los que trabajaba. Debo agradecer mucho a Michel. Su actitud intelectual, tal vez más que sus palabras, formó parte de mis configuraciones intelectuales. Michel pasará a la historia como un hombre inclasificable y complejo. Siempre intentamos clasificarlo como freudiano y en otras corrientes, sin que por ello lo fuera. D

\section{Bibliografía}

Certeau, Michel de, 1963, “La conversion du missionnaire”, en Christus, t. 10, núm. 40, pp. 514-533.

__, 1964a, "Le temps des conflits", en Christus, núm. 41, pp. 77-90.

__ 1964b, “Donner la parole”, en Christus, núm. 44, pp. 438-456.

__ 1964c, "Situations culturelles, vocation spirituelle”, en Christus, t. 11, núm. 43, pp. 294-313.

__. 1965a, "Unité et division des catholiques", en Christus, núm. 47, pp. 365-383.

—_, 1965b, "Comme un voleur", en Christus, núm. 45, pp. 25-41.

—_, 1966, “L'épreuve du temps”, en Christus, t. 13, núm. 51, p. 314.

_., 1968, "Prendre la parole”, en Études, junio-julio.

__. 1970, “L'expérience spirituelle”, en Christus, t. 17, núm. 68, pp. 488-498.

__ 1973, “L'espace du désir ou le 'fondement' des Exercices spirituels", en Christus, t. 20, núm. 77, p. 118.

__, 1982, La fable mystique (XVIe-XVII' siècle), t. I, Gallimard (Bibliothèque des Histoires), París.

—, 1987, La faiblesse de croire, Seuil, París.

__, 1993, La escritura de la historia, Universidad Iberoamericana, México.

—_, 1994, La fábula mística: siglos XVI-XVII, Universidad Iberoamericana, México.

__. 1995, La toma de la palabra y otros escritos políticos, Universidad Iberoamericana/Instituto Tecnológico y de Estudios Superiores de Occidente, México.

—_, 1996, La invención de lo cotidiano, vol. 1: Artes de hacer, Universidad Iberoamericana, México.

__., 2003a, Historia y psicoanálisis: entre ciencia y ficción, Universidad Iberoamericana/Instituto Tecnológico y de Estudios Superiores de Occidente, México.

_- 2003b, La faiblesse de croire, Seuil, París.

__. 2006a, La debilidad de creer, Katz, Buenos Aires.

—_, 2006b, La fábula mística, siglos XVI-XVII, Siruela, Madrid.

__ 2012, La posesión de Loudun, Universidad Iberoamericana, México.

Certeau, Michel de, Luce Giard y Pierre Mayol, 1999, La invención de lo cotidiano, vol. 2: Habitar; cocinar, Universidad Iberoamericana/Instituto Tecnológico y de Estudios Superiores de Occidente/Centro de Estudios Mexicanos y Centroamericanos, México. 
Certeau, Michel de, Dominique Julia y Jacques Revel, 2008, Una politica de la lengua. La Revolución francesa y las lenguas locales: la encuesta de Gregorio, Universidad Iberoamericana, México.

Chenu, Marie-Dominique, 1937, Une école de théologie: le Saulchoir, Tournai Casterman.

Daniélou, Jean, 1948, Origène, La Table Ronde, París.

,1950, Sacramentum futuri. Études sur les origines de la typologie biblique, Beauchesne, París.

, 1951, Bible et liturgie, la théologie biblique des sacrements et des fêtes d'après les Pères de l'Église, Cerf, París.

Dosse, François, 2003, Michel de Certeau. El caminante herido, Universidad Iberoamericana, México.

Favre, Pierre Bienheureux, 1960, Mémorial, Desclée De Brouwer (Christus), París.

Mendiola, Alfonso, 2014, Michel de Certeau. Epistemología, erótica y duelo, Ediciones Navarra, México.

Moingt, Joseph, 2010, Croire quand même, Temps Présent, París.

Sonier de Lubac, Henri, 1938, Catholicisme, París, Cerf.

- 1946, Surnaturel, Aubier, París.

Surin, Jean-Joseph, 1963 [1663-1667], Guide spirituel pour la perfection, Desclée de Brouwer, París. 